\title{
Influence of Second Language (L2) Proficiency on the Measure of 'Spatiotemporal Index' of Bilabial Utterances in Typical Kannada (L1) English (L2) Bilingual Speakers
}

Mahesh B.V.M \& Manjula, R.

Mahesh B.V.M., Junior Research Fellow, Department of Speech Language Pathology, All India Institute of Speech and Hearing, Manasagangothri, Mysore, Karnataka State, India maheshslp@gmail.com

Manjula, R., Professor in Speech Pathology, Department of Speech Language Pathology, All India Institute of Speech and Hearing, Manasagangothri, Mysore, Karnataka State, India

rmanjula08@gmail.com

\section{ABSTRACT}

The Spatiotemporal Index (STI) of Lower lip (LL) across L1 (Kannada) and L2 (English) in High Proficient (HP)/Early and 'Low Proficient (LP)/Late typical Kannada (L1)-English (L2) bilinguals was analyzed. A bilabial utterance pair matched for syllable structure and length, phonetic complexity, and overall duration across L1 and L2 were uttered 10 times in each language randomly using language switching paradigm by 'HP/Early' $(n=7)$ and 'LP/Late' $(n=7)$ bilinguals. The mean STI was significantly different across languages and L2 language proficiency, supporting the use of differential speech motor control strategies by participants to maintain phonetic distinctiveness across languages. The STI was more variable in HP/Early bilinguals across L1 and L2 than LP/Late bilinguals and HP/Early bilinguals showed higher variability in Kannada (L1), reflecting higher organizational flexibility and movement control along with successful suppression of the non target language (L2). The mean STI in LP/Late bilinguals did not differ significantly across languages suggesting reduced movement flexibility and inability to suppress the interfering effect of L1 on L2. The results are discussed in the perspective of the measure of STI reflecting an intra articulatory global movement variability that is sensitive in understanding the movement control differences in the speech production of bilinguals. The findings are also discussed in the backdrop of bilingual speech production models and possible influence of 'Cross Linguistic Interference' on articulatory movement stability across L1 and L2.

\section{Indexing terms/Keywords}

High Proficiency; Low Proficiency; Early bilingual; Late bilingual; Kannada; Spatiotemporal Index; Lower Lip, Cross Linguistic Interference; Articulograph AG500;

\section{Academic Discipline And Sub-Disciplines}

Speech and Hearing; Speech Language Pathology;

\section{SUBJECT CLASSIFICATION}

Speech Language Pathology

\section{TYPE (METHOD/APPROACH)}

Quasi experimental study.

\section{Council for Innovative Research}

Peer Review Research Publishing System

\section{Journal: Journal of Advances in Linguistics}

\author{
Vol.6, No 1 \\ editor@cirjal.com \\ jaleditoronline@gmail.com, www.cirjal.com
}




\section{INTRODUCTION}

Earlier studies on speech production of bilinguals focused majorly on the 'Age of Acquisition' (AoA) effects of segmental and non segmental aspects mostly driven by Lenneberg's (1976) Critical Period Hypothesis (CPH). Studies on SpanishEnglish, French-English, Italian-English bilinguals showed higher accuracy in vowel production, voice onset time (VOT), consonant duration and L2 accent in early bilinguals compared to late bilinguals and in several instances, the early bilinguals were comparable to the L2 monolinguals (Flege, 1991; Mack, 1989; Munro, Flege \& Mackay, 1996; Schmidt \& Flege, 1996). AoA effects were also observed across phonological features (Flege, Yeni-Komshian \& Liu, 1999; Munro et al. 1996) and grammar/morphosyntax (Birdsong \& Molis, 2001; Jia, Aronson \& Wu, 2002). However, there were studies that contradicted the AoA effects for the measure of VOT, L2 production accuracy and accent (Birdsong, 1992; Bongaerts, Van Summeren, Planken \& Schills, 1997; Flege, Munro \& Mackay, 1995; Magloire \& Green, 1999).

Recent literature raises questions on the validity of attributing age related differences in the bilinguals' speech production to biological/maturational constraints. Significant differences seen between L2 of early bilinguals and L2 monolinguals raises questions as to the advantage of learning L2 in the putative sensitive (critical) period (Flege, Mackay \& Meador, 1999; Flege, Schirru \& Mackay, 2003; Mackay, Flege, Piske \& Schirru, 2001). Some variables correlating with AoA effects such as length of residence (Flege et al., 1995), motivation (Moyer, 2004), language use of L1 or L2 (Flege et al., 1995; Jia \& Aaronson, 2003), and L2 language proficiency (Perani et al.,1998; Warternburger et al. 2003) are reported to influence L2 speech production. Hence, it is important to address these variables along with the possible influence of sensitive period. The current study is proposed to understand the speech production differences in bilinguals as a factor of age of exposure and L2 language proficiency.

At the phonological level, bilingual speakers exhibit shared 'phonological space' of L1 and L2 (Flege, 1995), and therefore it is hypothesized that it is difficult for a bilingual to completely deactivate the properties of a language while speaking in the other (Flege, Frieda \& Nowaza, 1997). Since the phonological space is merged, there are possibilities of cross linguistic interference which may be influenced by the individual's strength in L1, or L2, as proposed by Green's Inhibitory control model (Green, 1998). The model states that more processing resources are required to inhibit the L2 influence when there is higher proficiency in a language and since inhibition is reactive in nature, higher processing resources are again required to reactivate the inhibited language. Some of the studies have shown that there is an influence of L2 language on speech production skills due to the mediation of cross linguistic interference in bilinguals. Highly experienced English speakers of Korean (L1) and Italian (L1) native background produced shorter utterance durations in English compared to the less experienced counterparts which was attributed to the suppression of cross linguistic influence of $L 1$ on L2 (Guion, Flege, Liu \& Yeni-Komshian, 2000). Guion et al. (2000, p. 225) expressed the opinion that "more established the L1 is at the time of first exposure to L2, more it interferes with L2 production and the greater are the processing resources required to suppress it". Mackay and Flege (2004) reported similar findings of increased duration in the production of L2 sentences by late Italian (L1) English (L2) bilinguals and an opposite trend for early bilinguals.

Although studies using perceptual and acoustic measures have reported the influence of language proficiency on speech production of bilinguals, an explanation regarding the physiological underpinnings for the observed speech effects is generally lacking. This shortcoming can be addressed using speech kinematic analysis paradigms which yields either point measures of Amplitude, Displacement and Velocity (Ackermann, Hertrich \& Scharf, 1995; Zimmermann, 1980) or whole trajectory measures such as Spatiotemporal Index (STI), Lip Aperture Variability (LAVAR) and Lower lip/Jaw complex (Chakraborty, 2012; Smith, Goffman, Zelaznik, Ying \& McGillem, 1995) using any one of the equipment such as Strain Guage, Optotrak or Electromagnetic Midsagittal Articulography (EMMA). This study used one of the whole trajectory measure called Spatiotemporal Index (STI) which is a composite measure of spatial and temporal variability computed for a target utterance iterated predetermined number of times (Smith et al., 1995). STI is useful in understanding the trial-to-trial intra articulatory variability of upper lip, lower lip, tongue, and jaw and so on for repeated phonetic segments such as syllable, words, phrases and sentences. Studies using STI measure have documented that the language experience influences the physiological dynamics of speech motor control in children, adults and geriatrics. Children were shown to be more variable in their articulatory movement trajectories compared to adults due to less mature speech and language systems and geriatric population were shown to be more variable in movement control due to a decline in speech motor control (Goffman \& Smith, 1999; Smith \& Goffman, 1998; Smith \& Zelaznik, 2004; Walsh \& Smith, 2002). STI is also considered to be a sensitive measure to understand the influence of linguistic variables such as increasing utterance length and complexity (Maner, Smith \& Grayson, 2000; Sadagopan \& Smith, 2008).

Very few studies have analyzed the articulatory kinematic correlates of speech in bilingual population (Chakraborty, 2012; Chakraborty, Goffman \& Smith, 2008; Chakraborty \& Shanmugam, 2011; Nissen, Dromey \& Wheeler, 2007; Sasisekaran \& Weisberg, 2013). Further, there are very few studies which addressed the issue of language proficiency on articulatory stability (Chakraborty, 2012; Chakraborty, Goffman \& Smith, 2008). Nissen, Dromey and Wheeler (2007) studied high proficient English (L2) speakers from native Spanish (L1) and Korean (L1) background wherein, English was shown to have longer tongue stroke speed and duration compared to Spanish and Korean languages. The findings were attributed to the lower articulatory flexibility and diminished automaticity in L2 over L1. Sasisekaran and Weisberg (2013) reported a marginal bilingual advantage in the nonword repetition of bilinguals compared to monolinguals when a range of L2 language pairs and proficiency levels were tested. However, the bilingual advantage seen in the repetition of nonword utterances was not seen in the speech motor variability measure of LAVAR (one of the commonly used speech motor variability measure that evaluates the coordinative dynamics of upper lip, lower lip and jaw) in bilinguals. Chakraborty, Goffman \& Smith (2008) documented that LAVAR, was found to be marginally variable in Bengali (L1) compared to English (L2) in early/high proficient bilinguals but no such differences were reported for late/low proficient bilinguals. Further, the study did not report any differences between languages and language proficiency groups with respect to the 
articulatory stability. The authors viewed the higher LAVAR in L1 of early/high proficient bilinguals as due to increased articulatory flexibility and explained the possible influence of cross linguistic interference of L2 over L1 in early Bengali English bilinguals. Similar findings were reported in a later study by Chakraborthy (2012), which was conducted on the same population matched for age of exposure, language proficiency and academic exposure. Based on these findings, Chakraborthy (2012) hypothesized that LAVAR may not be influenced by phonetic differences of L1 and L2 as it requires a higher order synergy that remains highly stable across languages of bilinguals.

The earlier studies that addressed the bilingual speech productions through speech kinematic measures, were limited with respect to the criteria adapted for selection of participants based on age of acquisition, language proficiency, and language usage (Nissen, Dromey and Wheeler, 2007); variability in L2 language of the participants (Sasisekaran \& Weisberg, 2013); procedure used for data analysis (Nissen, Dromey \& Wheeler, 2007; Sasisekaran \& Weisberg, 2013) type of stimuli used across L1 and L2 (Chakraborty, 2012; Chakraborty et al., 2008). In the studies by Chakraborty (2012) and Chakraborty et al. (2008), stimuli pairs in L1 and L2 were matched with respect to the number and type of bilabial syllables; but not controlled for occurrences of consonants other than bilabials, overall length of the word before a pause boundary, and inter word pauses. No attempts were made to control the durational differences of selected pairs across languages which could have potentially influenced the measured indices of speech motor control on typical bilinguals.

Majority of the studies using kinematic measures follow the traditional approach of repeating the target utterances in a specific language for a predetermined number of times to understand the articulatory control dynamics (Goffman \& Smith, 1999; Maner, Smith \& Grayson, 2000; Sadagoppan \& Smith, 2008; Smith \& Goffman, 1998; Smith \& Zelaznik, 2004; Smith et al., 1995; Walsh \& Smith, 2002). Although this procedure is highly recommended for studies using kinematic procedures, in this study, it is hypothesized that this procedure may not facilitate the observation of interaction of speech motor control and language interactions in bilingual speakers. The reason being that repetition of a target phrase involves construction of a core motor plan at the beginning of the utterance with subsequent production of the target getting highly automatized, and this in turn may not place greater demand for change in core motor plans. Thus, it may not have the potential to elicit changes or differences in the speech produced across the two languages in the bilingual speakers. If on the other hand, the utterances of two known languages of a bilingual is interspersed, there is increased demand placed for construction of different motor schemas in motor planning of the higher centers depending on the language used and this could further facilitate bringing about the differences, if any, in the speech of a bilingual. Till date, studies using kinematic analysis have not shown differences when groups were collapsed on the basis of the AoA and L2 language proficiency. However, behavioral studies which used language switching tasks (Meuter \& Allport, 1999) have reported differences when AoA and L2 language proficiency were considered as factors. Emerging evidences in bilingual literature have revealed that when bilingual speakers switched from L1 to L2 or L2 to L1, differences in terms of phonological and lexical selection processes were evident and this in turn influenced speech production across languages of bilinguals (Costa \& Santesteban, 2004; Costa, Santesteban \& Ivanova, 2006; Meuter \& Allport, 1999). Abrahamsson and Hyltenstam (2009) cautioned that studies intending to measure the speech production differences in bilinguals should consider stimulus selection and task complexity as important factors to bring out the differences between L1 and L2. In this study, language switching paradigm is used, wherein the matched pair of stimuli in L1 and L2 is visually presented to the participants by randomly mixing the stimuli of the languages (L1 \& L2) on HP/Early and LP/Late L2 proficient typical Kannada (L1) English (L2) bilingual speakers.

Majority of the earlier studies reported data on individuals who were immigrant nationals of Indian sub continent, China and Europe to an English speaking country like United States (US), Canada or United Kingdom (UK). The nature, type and distribution of bilingualism in India are quite different than the western context. There are very few studies which have used kinematic analysis to analyze the bilingual speech by controlling various attributes of speech in L1-L2 which could potentially influence the type and nature of processing involved in L1-L2. In this study, the variability in speech motor control of bilingual speakers is addressed, wherein participants with variable degrees of exposure to English (L2) but living in an L1 speaking environment, using L1 as a major language to communicate on a day-to-day basis were included. For the same reason, in this study, the term 'Age of Exposure' is used instead of 'Age of Acquisition/Arrival' (AoA), because the former term corroborates with learning a foreign language in a formal setting, for instance, schooling environment, which is generally the case in Indian scenario contrary to AoA which refers to acquisition of a second language typically as an immigrant, immersed in a L2 speaking environment (Birdsong, 2006). Another dimension of this study is the use of language switching paradigm where the stimulus tokens across Kannada (L1) and English (L2) languages were randomized across the participants to minimize the sensitivity to order (in terms of language) during the presentation of stimuli. The study also aimed to understand how the construct of language proficiency in L2 influenced a variability measure like STI.

The study aimed to evaluate the influence of L2 language proficiency on the measure of Spatio Temporal Index (STI) of Lower Lip (LL) in Kannada (L1) - English (L2) bilinguals using language switching paradigm. Kannada is a major language under the Dravidian language family which is spoken predominantly in the state of Karnataka in India. This is also spoken by native Kannada speakers in the neighboring states of Andhra, Telangana, Kerala, Tamil Nadu, Goa and Maharashtra. Kannada has an officially recognized language status in the Karnataka State and is spoken by nearly 70 million people as per the Government of India, Ministry of Home Affairs, Office of the Registrar General and Census Commissioner, India (2011). In this study Kannada (L1) - English (2) bilinguals were divided into two groups: High Proficient (HP)/Early and Low Proficient (LP)/Late bilingual groups based on their language proficiency in English using reaction time measure of a lexical decision task along with self rated L2 proficiency scores of International Second Language Proficiency Rating Scale (ISLPR). 
The study assumes the following hypotheses:

a) The mean STI scores of LL for the bilabial utterance of Kannada (L1) will be lower than English (L2) as Kannada is a more practiced and frequently used language for day to day communication by the typical Kannada-English bilingual speakers.

b) The speech motor variability measure of Spatiotemporal Index (STI) will be different in the High Proficient (HP)/Early and Low Proficient (LP)/Late L2 bilingual speakers.

c) If cross linguistic interference phenomenon occurs, then HP/Early L2 speakers will show more variability in the mean STI scores of L1 due to suppression of L2 whereas LP/Late L2 speakers will show higher variability in L2 as a result of inhibitory influence of $L 1$.

\section{METHOD}

\section{Participants}

Fourteen Kannada (L1)-English (L2) male bilingual speakers in the age range of 18-30 years $(M=23.28, S D=3.40)$ were included in the study. All the participants spoke Kannada as their native language and were residents of Mysuru district in the state of Karnataka wherein Kannada is spoken by majority of the population. All the participants spoke standard Kannada dialect of Mysuru, Karnataka, and could not speak any other dialect of Kannada language. Participants were exposed to English during their schooling in formal educational set ups. Participants who had a positive history of delay/deviation in language, oro-facial/structural anomalies, hearing problems, psychological problems and those who were under medication for illness and diseases were not included. Informed written consent was obtained from all the participants before the experiment and clearance from the Ethical Board of the institution where the study was conducted was obtained before carrying out the experiments.

Language proficiency in English was estimated using two measures that included:

1) "Lexical priming task to check language proficiency in Bilinguals (Kannada-English)" (Prema, Abhishek \& Prarthana, 2009). This test was developed with the objective of measuring language proficiency in Kannada and English languages and included the following subtasks:
a) Translation Equivalent priming
(TE) b) Semantically Related Priming (SR) and

c) Semantically Unrelated Priming (SUR) tasks. The tasks use lexical judgement, wherein reaction time is measured to document the language proficiency of Kannada- English bilinguals. In this study, only priming tasks of TE and SR in English (L2) language were utilized to group the participants based on English language proficiency.

2) "International Second Language Proficiency Rating Scale" (ISLPR) (Ingram \& Wylie, 1997). ISLPR is a widely used rating scale measure used to document English language proficiency under four linguistic skills i.e., Listening, Speaking, Reading and Writing rated on a 6 point scale between "0" to "5" (with intermediate "+" and " - "levels, which totally makes up to 12 levels in each linguistic skill).

\section{Pilot study: To establish the criteria for categorizing participants under high and low proficiency groups.}

A pilot study was conducted in order to arrive at a criterion to categorize participants under either high or low proficiency group. This included 40 (20 males and 20 females) typical Kannada-English bilingual participants (who were not a part of the study) in the age range of $18-30$ years $(M=24.2, S D=2.63)$. The lexical decision tasks and ISLPR tasks were administered on these participants. In both TE and SR priming tasks, participants were presented with 100 pairs of prime and target pairs (in each task) and asked to ignore the L1 prime and judge the L2 target as a 'word' or a 'non-word'. The reaction time for the target pairs judged correctly were measured and the mean reaction time for TE and SR priming tasks were calculated separately. The scores obtained on the lexical decision task which correlated with the domains of the ISLPR task was used to categorize the groups as high or low proficient.

Among the 40 participants of the pilot study, data obtained from 5 TE $(n=35)$ and 1 SR $(n=39)$ were eliminated as these were identified as significant outliers using 'box plot' technique and all of these had unusually longer or shorter reaction times. 'Mean reaction time' of both TE and SR priming tasks were taken as 'reference' and this was used for further categorization of groups. Accordingly, the mean score in TE task was $971.77 \mathrm{~ms}(S D=111.89)$ and SR task was 1015.12 $\mathrm{ms}(S D=155.27)$. Spearman's rank correlation was computed to establish correlation for the two task sets and it was found that TE priming task negatively correlated with few of the ISLPR domains such as a) Reading $(\rho=-0.419,[p]=0.01)$ and b) Writing $(\rho=-0.533, p<0.01)$. SR priming task correlated with ISLPR domains such as a) Speaking $(\rho=-0.316, p=$ $0.05)$ and $b)$ Writing $(\rho=-0.385, p=0.01)$. Since the study aimed at measuring the motor stability in the speech of the bilinguals, SR priming task and speaking domain from ISLPR was chosen to subgroup participants into high or low proficient groups. Therefore, participants who obtained shorter reaction time in SR priming (below the mean score, i.e., $<1015.12 \mathrm{~ms}$ ), viz., with better linguistic processing speed, and a self rating score of ' $>3$ ' (greater than ' 3 ' in ISLPR scale) were categorized as 'high proficiency' group. On the other hand, those who obtained longer reaction time in SR priming (above the mean score, i.e., $>1015.12 \mathrm{~ms}$ ), viz., poorer linguistic processing speed, and a self rating score of '<3' (lesser than ' 3 ' in ISLPR scale) were grouped into 'low proficiency' group. Following these criteria, 7 participants were included under High Proficiency (HP) group and the remaining 7 were included under Low Proficiency (LP) group. While administering the ISLPR scale, information regarding the age of exposure to English was also obtained. Interestingly, those 
individuals who were classified as HP were found to be early bilinguals $(n=7)$ who were exposed to English below 5 years of age and the LP group were late bilinguals $(n=7)$ who were exposed to English after 10 years of age.

\section{Criteria used to determine exposure to multiple languages and Language Use in the participants.}

As India is a multilingual country, most of the citizens speak more than two languages. Since use of more than two languages other than the languages of interest in this study (Kannada and English) could have a potential influence on the articulatory kinematic measures of the study, a checklist was prepared by the investigators and information collected from the participants to rule out such influences. Information regarding participants' third (L3), fourth (L4) and fifth (L5) languages were gathered in the checklist. All the participants, including high and low proficient speakers were found to be exposed to Hindi formally in the schooling years from $5^{\text {th }}$ grade to $10^{\text {th }}$ grade. However, the participants rating on the self rated language proficiency scale showed a rating of less than 1 in a 3 point rating scale (' 0 ' = No proficiency, $1=$ low, $2=$ good, 3 = native like proficiency) and none of participants reported of studying or using Hindi at the college level. While this study was undertaken, none of them used Hindi or any other language other than Kannada and English for day-to-day communication.

A self reported language usage of Kannada and English was measured through LEAP-Q, adapted for Indian population for Kannada English bilinguals (Maitreyee \& Goswami, 2009). Information regarding L1 and L2 language use in various contexts such as interacting with friends, neighbours, watching TV, reading books, newspapers, internet surfing etc was collected across L1 and L2 and the same was calculated as percentage of usage of Kannada and English languages for each participant across HP and LP groups (shown in figure 1). From Figure 1, it is seen that the high proficient English speakers used both the languages approximately to an equal extent whereas a clear domination of Kannada language use was seen in low proficient English speakers.
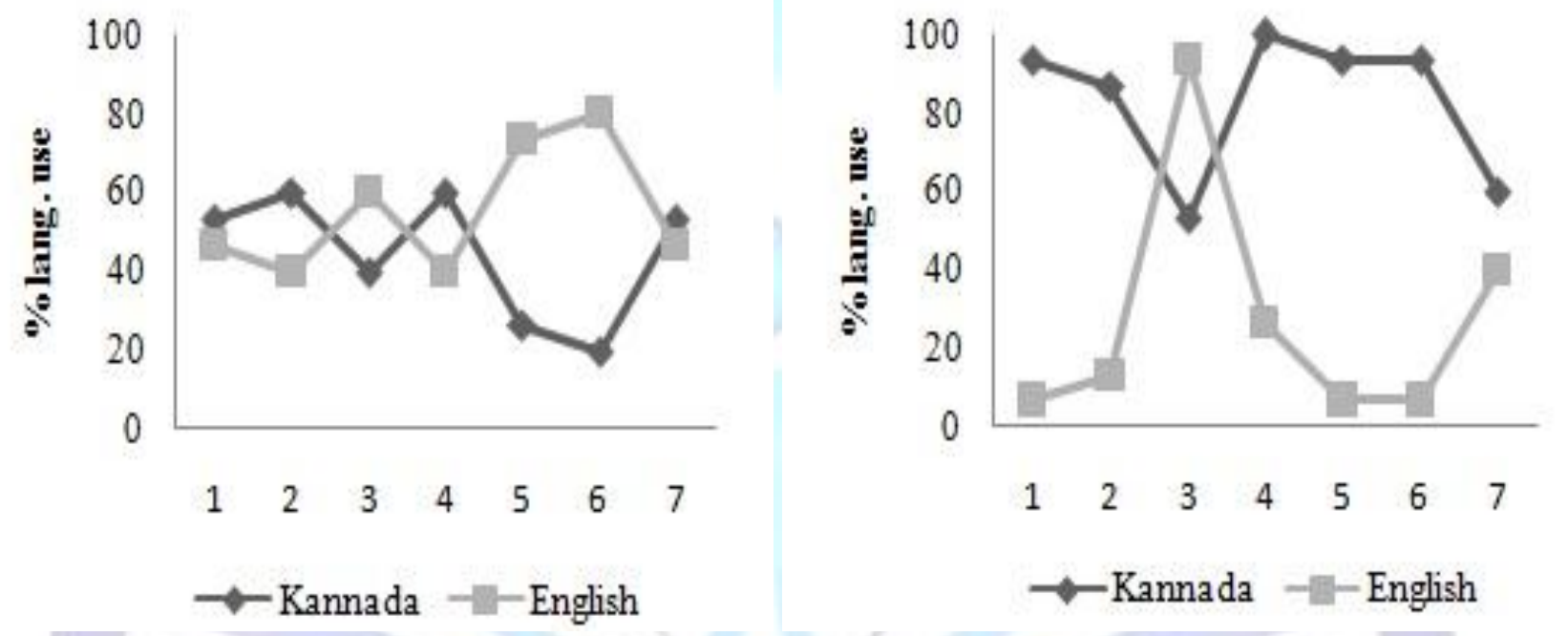

Figure 1: Percentage of L1 and L2 use in a) High proficient bilinguals and b) Low proficient bilingual participants

\section{Materials}

As the target was to study the bilabial articulatory movement of lower lip (LL), bilabial consonants such as $/ \mathrm{pa} /, / \mathrm{ba} /, / \mathrm{b}^{\mathrm{h}} \mathrm{a} /$ (only in Kannada) and /ma/ were selected and phrases were selected using these bilabial consonants in Kannada and English. Phrases with bilabial consonants that were highly comparable in their phonetic structure were selected from Kannada and English Dictionaries, books and standard texts. A standard phrase was first constructed in Kannada using the bilabial consonants. Following this, several English phrases with similar phonetic structure as in the Kannada language were selected. These bilabial stimuli phrase pairs in Kannada and English languages were given to two linguists (KannadaEnglish bilingual males) to rate for phonetic balance and syllable length (number of syllables and syllable duration) using a 3-point rating scale (where ' 0 ' = poor, ' 1 ' = fair and ' 2 ' = good). Only those stimuli phrase pairs rated as ' 2 ' by both the linguists were chosen for the study. Apart from rating the stimuli, based on the feedback obtained from the linguists, the stimuli pairs were matched for duration to reduce the potential phonetic differences across languages. A pilot study was conducted wherein the stimuli pairs were uttered by 6 Kannada-English typical bilinguals ( 3 Males \& 3 Females in the age range of 18-30 years) were audio recorded using PRAAT software (Boersma \& Weenink, 2013). Participants were instructed to iterate each target utterance five times in their habitual speaking rate and loudness. Among these 5 iterations, the middle three were chosen and analyzed for their overall duration. Mean duration and Standard Deviation of the same is represented in Table 1. 
Table 1. Details of stimuli pairs with respect to the syllable structure, utterance length (in syllables), type of bilabial sounds, number of inter word pauses, mean \& sd for duration of the stimuli.

\begin{tabular}{|c|c|c|c|c|c|c|}
\hline \multirow[t]{2}{*}{ Languages } & \multirow{2}{*}{$\begin{array}{c}\text { Stimuli } \\
\text { pairs }\end{array}$} & \multirow{2}{*}{$\begin{array}{c}\text { No. of } \\
\text { syllables }\end{array}$} & \multicolumn{2}{|c|}{$\begin{array}{l}\text { Type of bilabial } \\
\text { sounds }\end{array}$} & \multirow{2}{*}{$\begin{array}{l}\text { No. of } \\
\text { Inter } \\
\text { word } \\
\text { pauses }\end{array}$} & \multirow{2}{*}{$\begin{array}{c}\text { Mean duration } \\
\text { (SD) } \\
\text { (in ms) }\end{array}$} \\
\hline & & & Unvoiced & Voiced & & \\
\hline \multirow[t]{2}{*}{ Kannada } & $/ b^{h} I$ məna $p_{I} \square p_{I} /$ & 5 & 2 & 2 & 1 & 1250.76 \\
\hline & CVCVCV CVCV & & & & & $(92.54)$ \\
\hline \multirow[t]{2}{*}{ English } & /ba m I $n_{I}$ 's $p a: p ə /$ & 5 & 2 & 2 & 1 & 1347.66 \\
\hline & cvevcre cvev & & & & & $(149.43)$ \\
\hline
\end{tabular}

Comparison of mean duration of target utterances using Paired ' $\mathrm{t}$ ' test revealed no significant difference between one of the pair (/b ${ }_{I}{ }_{I}$ məna $p_{I} \square p_{I} /$ and $/ b a m_{I} n_{I}$ 's $\left.p a: p \partial /\right)[t(5)=1.776, p=0.13]$, suggesting that the stimuli duration was comparable between the languages. Therefore, $/ b^{h}{ }_{I}$ məna $p_{I} \square p_{I} /$ (meaning: $b^{h}$ ima's whistle) and $/ b a m_{I} n_{I}$ 's $p a: p \partial /$ (meaning: bamini's father) was chosen as the target stimuli pair for the study. The Indian proper noun 'bamini' was retained in English phrase as the study is on Indian population and this is one of the common proper names used in India. The aspirated voiced bilabial $\left[b^{h} a\right]$ was retained in Kannada stimulus as it was linguistically sensitive and exclusive to Kannada compared to English. It may be noted that the phonotactic rules in English do not allow for an aspirated voiced bilabial in the word initial position. Additional steps were also followed to ensure that phonetic differences between the target stimuli of the two languages were minimal. It was ensured that the syllable structure of the stimuli pair was mostly equal (very minimal differences were allowed) besides maintaining similar range of inter word pauses when spoken naturally. The consonants other than bilabials that were present in the stimuli were retained at similar syllable positions. Use of clusters and geminates were avoided.

\section{Apparatus}

The kinematic traces were analyzed using the equipment Articulograph AG500 (Carstens Medizinelektronik, Germany). The articulatory movement of LL was recorded and analyzed in the ' $Z$ ' axis (Superior-Inferior dimension). The electromagnetic transmitter coils in the Articulograph AG500 emit electromagnetic waves of alternating frequencies. When the electromagnetic waves impedes on the sensors (tiny electrodes attached on to the lower lip as test sensor and two reference sensors placed on the mastoid region and nasal bridge), AC voltage is generated in each of the sensors. The voltage generated in each sensor depends on its distance from the transmitters. Therefore, by computing the strength of the voltage generated in the sensors, an indirect measure of the distance of the test sensor and its movement as compared to the reference sensor can be measured. The articulatory movements were recorded at a sampling rate of $200 \mathrm{~Hz}$ along with the acoustic data with a sampling rate of $16 \mathrm{kHz}$. Before test recording, the system is calibrated according to the procedures specified by the manufacturers. Video recording was also carried out while the participants uttered the stimuli in order to ensure the selection of fluent iterations for further analysis.

\section{Procedure}

\section{Step 1: Collecting language usage data and establishing L2 language proficiency.}

Using LEAP-Q (Maitreyee \& Goswami, 2009) questionnaire, history regarding the age of exposure to languages, medium of instruction in schooling, language usage in various speaking situations (interacting with friends, neighbours, watching TV, reading books, newspapers, internet surfing) were collected from the participants. The self rating of LEAP-Q took approximately 15 minutes.

The language proficiency was established by using Semantically Related lexical decision (SR) task in English (Prema, Abhishek \& Prarthana, 2009) and self rated score on the Speaking domain in ISLPR scale (Ingram \& Wylie, 1997). Initially, the mean reaction time measure was obtained using SR lexical decision task and this was followed by ISLPR self rating by the participants regarding their language proficiency in 'Speaking' domain. Administration of these tasks took approximately 20 minutes for each participant. Based on the criteria adopted after the pilot study (explained under the section on pilot study), 7 participants were grouped as high proficient and remaining 7 as low proficient in English. Based on the information obtained on the age of exposure and medium of instruction in schooling, participants were divided into two groups as follows: a) Those who learnt English below 5 years of age were grouped as early bilinguals ( $n=7)$ and b) those who learnt English after 10 years were categorized as late bilinguals $(n=7)$. Interestingly, early bilinguals were proficient in English whereas late bilinguals were low proficient in English and hence they were categorized under HP and LP group respectively.

\section{Step 2: Recording of kinematic data.}

Initially, the target skin sites where electrodes were placed was cleaned using a disinfectant and then electrodes were placed and secured firmly using a bio adhesive glue and bio tape. A total of 3 electrodes were used; two being reference electrodes that were attached to Mastoid and Nasal Bridge and the third one which was the test electrode was placed on the mid vermillion border of the lower lip (LL). The first investigator who was a Kannada English bilingual speaker himself 
carried out the data recording. Instructions were given to the participants in their preferred language (either Kannada or English). All the participants were instructed to repeat the stimuli using their habitual loudness and speaking rate. In order to familiarize the participants with the task, an 'auditory model' of pre recorded stimuli by a female speaker was played, for both the languages one after the other as the task involved the repetition of the utterances by switching the languages. Participants were asked to listen to the auditory model but they were not encouraged to practice before the recording since practice could influence speech motor stability. Stimuli sets were visually presented one after the other using Microsoft Powerpoint on a PC monitor which was placed in front of the participant. The participant was asked to look at the written stimuli that appeared on the monitor (which included stimuli of both the languages which were presented randomly) and utter each of the stimuli 10 times. The Kannada language stimuli were written in the Kannada script [భిeచునె డిeటి]. Each of the Kannada and English language stimuli was visually presented for 3 seconds on the computer screen. Four catch trials per 20 tokens were also used wherever two successive stimuli appeared in L1 or L2 only.

\section{Analysis}

The Displacement plots per subject per iteration was checked for artifacts due to dislocated sensors, interrupted recordings, non fluent utterances and these were excluded. Errors due to head movement were removed using the 'Normpos' module in the Articulograph AG500 (Carstens, Medizenelektronik). The displacement plots of LL were later imported into the MATLAB (MathWorks, Inc., 2012) software and the data was processed using MATLAB routines. Baseline drifts in the recorded plots were filtered by passing it through a band pass digital butterworth filter with a cut off frequency of $0.5 \mathrm{~Hz}$ to $6 \mathrm{~Hz}$. This was followed by the differentiation of the displacement signal to obtain plots of velocity versus time function using three point differentiation method. Similar to the procedure followed for the displacement signal, the derived velocity plot was also passed through band pass filter using digital butterworth filter to eliminate drifts and to smoothen the trajectories. The velocity data was used as the reference to segment the displacement trajectories of individual iterations. In order to carry out this procedure, at first the LL displacement plot along with LL velocity plot was lined up one below the other. The initial and final negative velocity peaks from the LL velocity plots was marked for each iteration which represented the opening movements of initial and final bilabial sound of each stimuli (Smith et al., 1995). For instance, the first negative peak associated with the bilabial opening $/ \mathrm{b}^{h_{i}}$ / of /bhimana/ and the last bilabial opening movement of /pi/ in /peepi/ was used to segment the plots of $/ \mathrm{b}^{\mathrm{h}}$ imana peepi/. The negative velocity served as the landmark to segment the displacement plots of individual iterations across languages. This procedure was carried out to segment all the iterated utterances of the stimuli in Kannada and English languages separately. Followed by the segmentation procedure, amplitude and time normalization of the plots was carried out (Smith et al.1995; Smith, Johnson, McGillem, \& Goffman, 2000). In this process, each segmented plot was extrapolated to a known factor of 1000 points using cubic spline interpolation procedure and the amplitude was normalized by dividing the mean of the plot by the Standard Deviation (Smith \& Goffman, 1998; Smith et al., 1995). On these amplitude-time normalized traces, standard deviations were calculated at every $20^{\text {th }}$ point upto 1000 points making upto 50 standard deviations for 10 fluent iterations and summed up to obtain the Spatiotemporal Index (STI). Therefore, STI values were obtained separately for each stimuli of each language for LL of each participant. The analysis for STI values were followed by superimposition of segmented displacement plots to obtain the graphic representation of the STI as a plot.

\section{RESULTS}

The mean STI were checked for normality using Kolmogorov Smirnov's test which showed that the data were normally distributed $(p>0.05)$. Further, Levene's test was run which revealed that the error variances for mean STI were homogenous across HP/Early and LP/Late bilingual groups $(p>0.05)$. The raw STI scores of the two groups are represented in Table 2.

Table 2. Raw STI scores of HP/Early and LP/Late Kannada English bilinguals across languages

\begin{tabular}{cccccc}
\hline & Participants & \multicolumn{2}{c}{ HP/early } & \multicolumn{2}{c}{ LP/late } \\
\cline { 2 - 6 } & Kannada & English & Kannada & English \\
& STI & STI & STI & STI \\
\hline Participant 1 & 16.32 & 12.11 & 9.70 & 9.22 \\
Participant 2 & 12.85 & 8.94 & 8.86 & 9.98 \\
Participant 3 & 16.78 & 10.31 & 9.39 & 8.09 \\
Participant 4 & 19.07 & 11.50 & 9.02 & 8.73 \\
Participant 5 & 13.64 & 10.79 & 12.34 & 13.52 \\
Participant 6 & 20.32 & 18.71 & 11.16 & 9.90 \\
Participant 7 & 18.57 & 13.84 & 11.51 & 11.39 \\
\hline
\end{tabular}




\section{Main effect for languages}

Using the Statistical Package for Social Sciences (SPSS) software (version 17), the mean STI data for languages in the two groups were subjected to Repeated measure ANOVA at 95\% confidence interval and 0.05 level of significance. Results revealed that there was a main effect for language $[F(1,12)=29.27, p<0.01]$ wherein Kannada had higher mean STI of LL compared to English. The mean STI and their Standard Deviation are represented in figure 2.

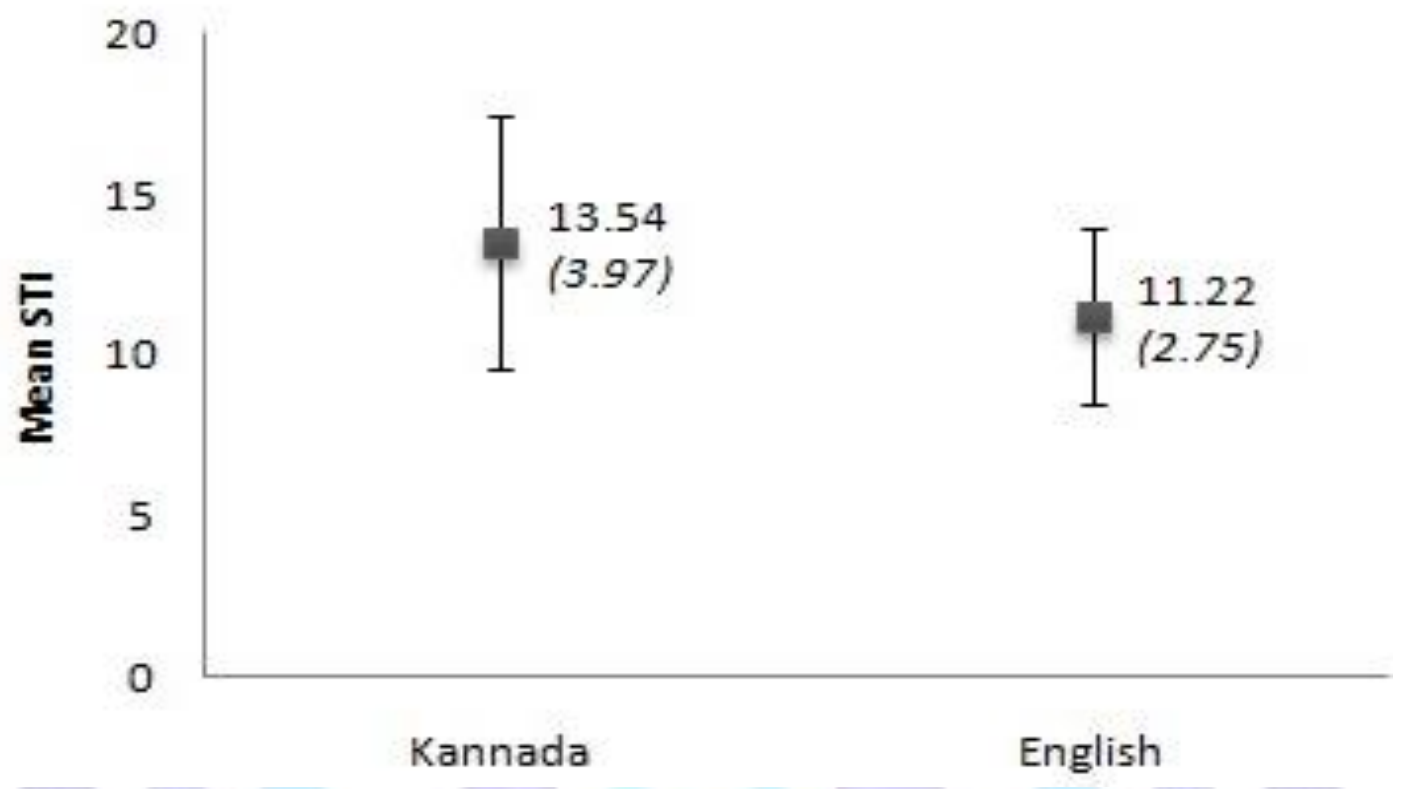

Figure 2: Mean STI and SD of LL across Kannada and English languages.

\section{Main effect for $\mathbf{1 2}$ language proficiency and other interaction effects}

The mean STI scores $[\mathrm{F}(1,12)=12.82, p<0.01]$ revealed a significant main effect for $\mathrm{L} 2$ language proficiency. The mean STI scores in the bilabial utterances of HP/Early bilingual cohorts [Kannada, $M=16.79, S D=2.78$; English, $M=12.31, S D$ = 3.20] were more variable compared to those of LP/Late bilingual cohorts [Kannada, $M=10.29, S D=1.36$; English, $M=$ $10.12, S D=1.83$ ] across languages [figure 3(b)]. An interaction between languages and L2 language proficiency $[\mathrm{F}(1,12)$ $=25.21, p<0.01]$ was also revealed. To understand the interaction of language and L2 language proficiency, Independent ' $t$ ' test was used to compare the mean STI of LL between HP/Early and LP/Late proficiency bilinguals within Kannada and English languages. A significant difference was revealed between the mean STI of the two groups for Kannada language $[\mathrm{t}(12)=5.54, p<0.01]$. But, no such differences were seen for English $[\mathrm{t}(12)=1.574, p=0.14]$. In the production of Kannada bilabial phrases, the mean STI of LL was higher in high proficient group compared to low proficient. In comparison, the mean STI of LL did not differ between the groups for the English phrases bilinguals [figure 3(a)].
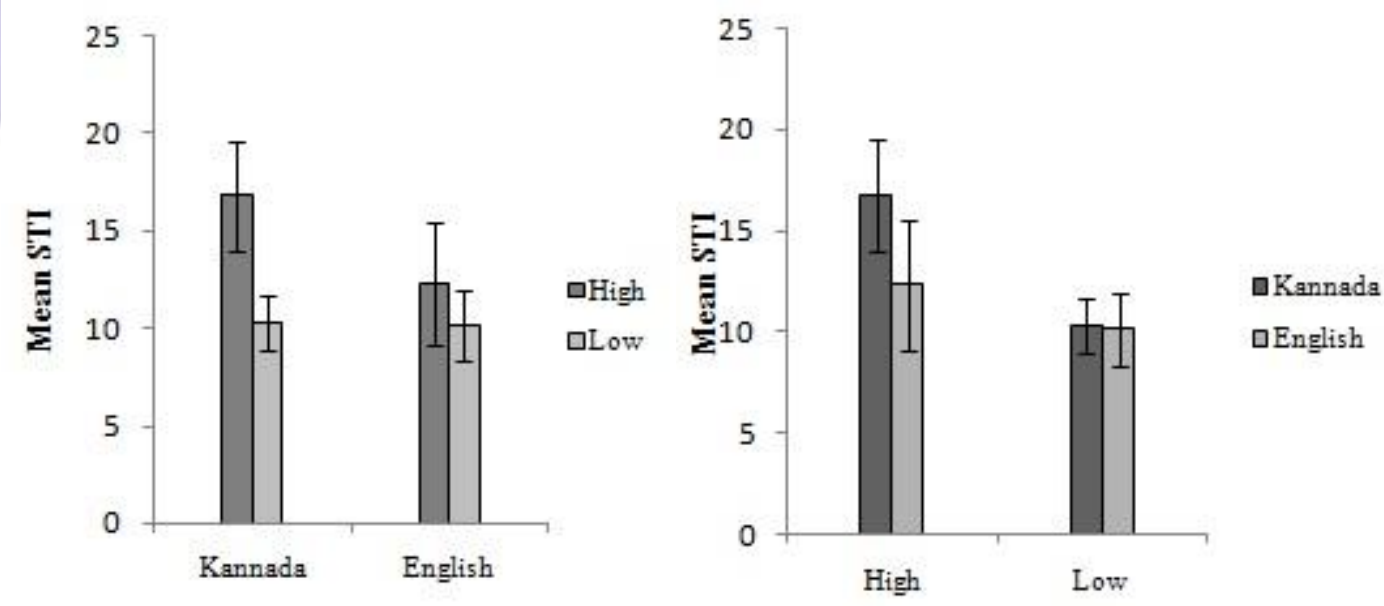

Figure 3: Mean STI and SD of LL for HP/early and LP/late bilingual groups for a) within language b) across languages. 

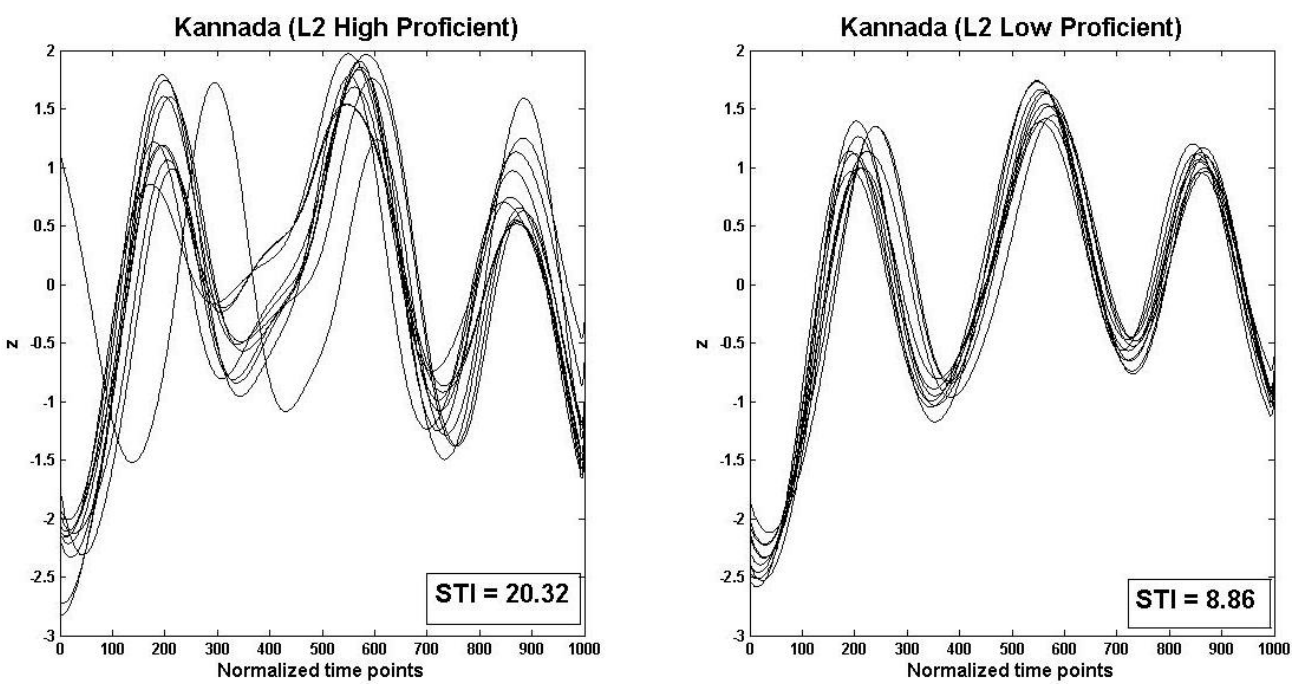

Figure 4: A sample of the normalized plot of Spatiotemporal Index (STI) of Lower Lip for the Kannada stimulus phrase $/ b^{h}$ I məna $p_{I} \square p_{I} /$ for a typical HP/Early and LP/Late Kannada English bilinguals. Note the higher mean STI variability in the HP/Early participant.

Paired-t test was used to compare the mean STI of LL between languages within HP/early and LP/late proficient groups. Mean STI differed significantly between Kannada and English in HP/Early bilinguals [t(6) $=5.81, p<0.01]$ whereas no differences were found between languages [figure 6] in LP/Late bilinguals [t(6) $=0.43, p=0.67$ ]. The HP/Early group showed differences in the mean STI of LL between languages, with more variability in Kannada compared to English [figure 3(b) \& 5].
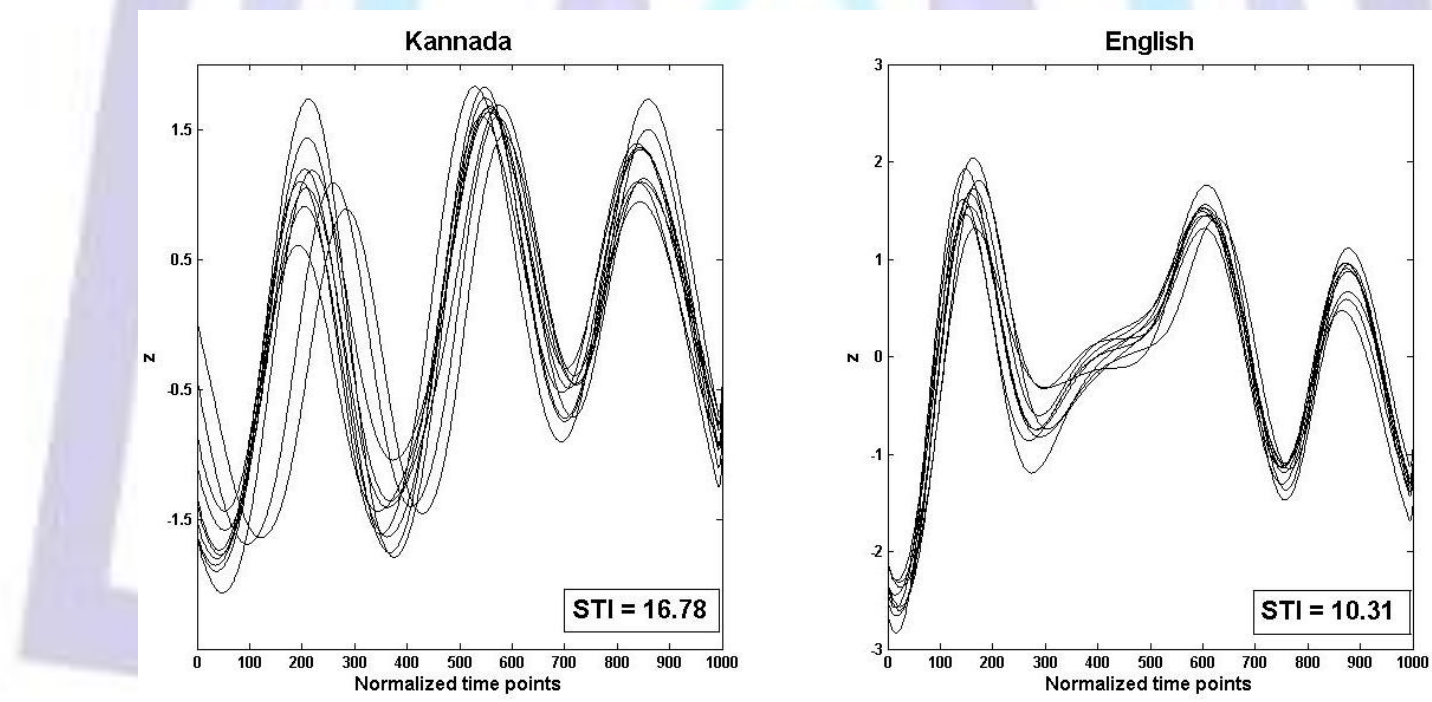

Figure 5: A sample of the normalized plot of Spatiotemporal Index (STI) of Lower Lip for the pair (/ $\mathbf{b}^{\mathrm{h}}$ I məna $p_{I} \square p_{I} /$ and /ba $m_{I} n_{I}$ 's $\left.p a: p ə /\right)$ in a typical high L2 proficient bilingual participant in Kannada and English. Note the higher STI variability in Kannada compared to English. 

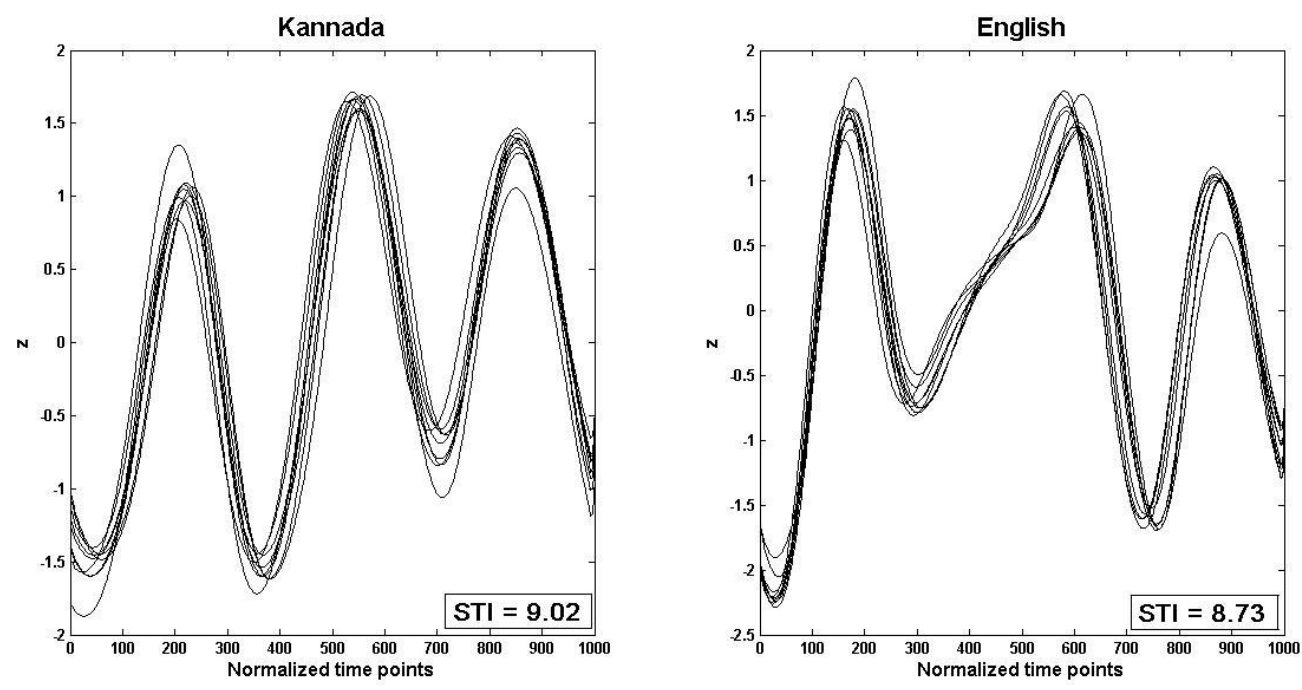

Figure 6: A sample of the normalized plot of Spatiotemporal Index (STI) for the pair (/b $\mathbf{b}^{\mathrm{h}}$ m mana $\mathrm{p}_{\mathrm{I}} \square \mathrm{pI}_{\mathrm{I}}$ and /ba $\mathrm{m}_{\mathrm{I}} \mathrm{n}_{\mathrm{I}}$ 's $\mathrm{pa}: \mathrm{p} /$ /) in a typical low L2 proficient bilingual participant in Kannada and English. Note that the STI variability across languages was comparable.

\section{DISCUSSION}

\section{Main effect for languages}

The mean STI was significantly higher for Kannada compared to English. Kannada was used more frequently (including $50 \%$ of high proficient individuals) in the daily activities of participants making it a motorically highly practiced language and hence the variation in the spoken utterances of Kannada was expected to be less compared to English. However, the results did not confirm with this notion and it was counter intuitive to the popular notion that any motor skill becomes more accurate and stable as the practice time, intensity and duration increases.

The higher STI variability in Kannada can be partially explained based on the nature of its phonetic production. Kannada belongs to Dravidian language family and has syllable structure pattern which ends typically with vowels (Manjulakshi, 2003). Due to this, the syllable ending with vowel in Kannada yields larger articulatory excursions thereby increasing the collision forces between the lips. The increased articulatory variability of LL in Kannada reflected in higher mean STI variability could possibly be attributed to such collision forces. Studies have shown that the inter speech postures utilized by a bilingual speaker across their L1 and L2 could be different (Gick, Wilson, Koch \& Cook, 2004; Wilson \& Gick, 2014). Continuing this observation, studies based on kinematic analysis have shown articulatory dynamic differences between L1 and L2 of bilinguals (Gick, Wilson, Koch \& Cook, 2004; Nissen, Dromey \& Wheeler, 2007; Wilson \& Gick, 2014). The inter speech postures being specific to a given language, prompts for a unique 'articulatory setting' which in turn allows for distinctive sounds either in L1/L2 or both. It is possible that the participants of this study implicitly adapted the strategy of distinctive 'articulatory setting' specific to a language which in turn led to differences in the mean STI between languages. In an earlier study, differences in the speed and durational aspects of speech were reported to be different across $L 1$ and L2 of Korean (L1) English (L2) and Spanish (L1) English (L2) bilinguals. However, generalization of the outcome seen for discrete single point measures such as speed and duration to a global measure such as STI requires further investigation (Nissen, Dromey \& Wheeler, 2007).

One other possible explanation for the observed differences across languages can be based on the minimal differences in the stimuli structure. The presence of a bilabial aspirant in the word initial position $\left[\mathrm{b}^{\mathrm{h}}\right]$ in Kannada might have increased the load on the speech motor system which in turn was reflected as higher mean STI variability in Kannada. Although aspirated stops are phonemic in Kannada, an increasing trend of unaspirating the aspirated sounds is noted in the general conversations of Kannada speakers as a means to reduce the speaking effort (Chengappa \& Devi, 2002). Therefore, insistence on production of aspirated sound in the Kannada stimulus may have influenced the participants to use newer articulatory space and distinctive articulatory configurations and this in turn could have led to higher variability in Kannada. The finding supports the presence of language specific articulatory motor routines. It may be noted that the investigators followed stringent procedures to select and match the stimuli pairs across Kannada and English in order to yield a stimuli pair which were highly comparable in terms of stimuli structure and durational properties across the two languages.

\section{Main effect for $\mathbf{2}$ language proficiency and other interaction effects}

The mean STI differed between HP/Early and LP/Late bilinguals. The differences in the articulatory variability between the groups was consistent with the prediction that HP/Early bilinguals show higher mean STI scores in their LL stability compared to LP/Late bilinguals. The finding suggests that the speech motor strategy utilized by HP/Early group to control articulatory execution differed from LP/Late bilinguals across L1 and L2. To the best of the knowledge of the investigators, similar studies on bilinguals using the variability measure of STI have not been conducted. 
Two points were evident from the results: a) HP/Early bilinguals showed more variability in Kannada compared to English whereas no such differences were seen in LP/Late group b) HP/Early proficiency group showed more variability in mean STI of Kannada compared to LP/Late group; whereas between group differences were not found for English. There seemed to be an interaction between 'languages' and 'L2 language proficiency'. The findings can be best explained using the cross linguistic interference phenomenon of Green's Inhibitory Control (IC) model (Green, 1998) along with the nature of speech learning that occurs in bilinguals using 'Speech Learning' model (Flege, 1995).

According to the 'Inhibitory control' model (Green, 1998), bilinguals experience cross linguistic interference depending on the strength of their language networks in L1 or L2. Since L1 and L2 compete in the lexical selection, depending on the context and environmental cues, one among the two languages of a bilingual is inhibited by using the mental process of selective inhibition, and the uninhibited language is facilitated by selectively activating its lexical nodes. Green (1998) hypothesized that the selective inhibition would place a burden on the allocated resources of the brain depending on which language gets inhibited. A dominant language requires higher resources to suppress, as well as to activate, compared to a non-dominant/weaker language. Grosjean (1982) elaborated on the direction of interference in bilinguals and suggested that the early bilinguals experience increased interference from L2 on L1 whereas late bilinguals experience interference from L1 on L2, as L1, in the majority of the cases, is a dominant language in late bilinguals. Basing on these observations, in this study, a higher variability of L1 in the HP/Early bilingual group is reasoned as due to the suppression of cross linguistic interference of L2. This is supported by the fact that HP/Early bilingual group showed higher variability in L1. Contrary to the observation however, the LP/late bilinguals did not show suppression of L1 as the mean STI variability was the same across L1 and L2. This indicates that there was a strong influence of L1 over L2, because if L1 was inhibited, then a higher variability in L2 was expected. The obtained findings are in line with the proposition made by Grosjean (1982) and consistent with some of the earlier acoustic and perceptual studies which reported an early bilingual advantage in resource allocation abilities to suppress a competing language compared to late bilinguals (Guion, Flege, Liu \& YeniKomshian, 2000; Mackay \& Flege, 2004).

Another interesting finding was that the L1 was more variable in HP/Early than LP/Late bilingual group [figure 3(a) \& 4]. As L1 was the native language of all the participants, a similar variability between the groups was expected. This finding suggests the presence of qualitative changes in the articulatory dynamics of L1 when they attain higher proficiency in $L 2$. It is speculated that a strong influence of L2 over L1 calls for restructuring of the L1 phonetic system in HP/Early bilinguals.

Speech Learning Model (Flege, 1995) proposes phonetic category dissimilation and phonetic category assimilation hypotheses to explain the speech production differences in bilinguals. According to phonetic category dissimilation hypothesis, when an L2 speech sound does not get identified as an instance of L1, a formation of separate or a new 'phonetic category' occurs for sounds of L2. In this study, it can be postulated that this was the case for HP/Early group of this study, because despite the stimuli pairs being similar in terms of phonetic structure in both the languages, the 'phonic units' were dissimilar according to the sensitivity of the languages and as a consequence, there was an observed difference in the mean STI scores across L1 and L2. It could be postulated that the aspirated bilabial [ $\left.b^{\mathrm{h}}\right]$ used in the Kannada stimulus phrase was recognized as a distinctive category compared to the unaspirated bilabial of English [b] by $\mathrm{HP} / \mathrm{early}$ group and hence a distinctive articulatory control was implemented to achieve the aspirated phonetic target by the participants. On the contrary, the 'phonetic category assimilation' can also be used to explain the findings seen for $\mathrm{LP} /$ late bilinguals. As there was no difference in mean STI scores, it could be hypothesized that late bilinguals could have realized the 'phonic units' of L2 as another instance of L1 which could have created merged phonological space between L1 and L2. Since there was a high possibility that the phonic elements could be realized as similar 'phones' across L1 and L2 and drawn from an assimilated 'common phonological space', the articulatory motor routines of L1 could be used to implement the L2 target, due to which the STI variability was similar across languages.

The findings reported here are partly similar to the results reported in an earlier study with a similar design and objective which showed that early/high proficient Bengali (L1)-English (L2) bilinguals were marginally variable in Bengali compared to English (Chakraborty et al., 2008). Although marginal difference existed in the speech motor variability in early/high proficient bilinguals, Chakraborty et al's study did not reveal group differences between 'early/high' and 'late/low' proficient groups. The language switching paradigm used in this study is cognitively more demanding and complex than the single language production task used by Chakraborthy et al. (2008). When participants repeat the stimuli of L1 and L2 alternatively and in a random order, the effective motor plan to execute the utterances needs to be reconstructed every time and this could have increased the processing load, which in turn was influenced by the interaction between language proficiency and articulatory dynamics in bilinguals. A single language production task, on the other hand, requires a core motor plan which is active in the first few repetitions and the same continues more automatically in the rest of the repetitions without placing much demand on the formulation of a new core motor plan. Even though both L1 and L2 networks are activated when a bilingual speaker produces speech, a conscious alteration and switching of stimuli to other language can increase the processing load on one or the other network as compared to a paradigm where only one language is used. The language switching paradigm used in this study, could be more sensitive in understanding the interaction of language and motor control that occur in bilinguals. However, further investigations are required with more evidences to augment these observations. Majority of the speech motor control studies propose that higher variability in STI is an indication of unstable motor systems, but this observation is viewed differently by Stathopoulos (1995). Variability could indicate any of the following process such as: less precision, increased organizational flexibility, less habituation of movement patterns or increased exploration that enhances motor learning (Sharkey \& Folkins, 1985). Therefore, higher variability in mean STI seen in L1 by HP/Early bilinguals could be attributed to the increased organizational flexibility, reflecting on the differential articulatory realizations across languages, indirectly suggesting differential sensitivity to the control of language specific articulatory configurations. On the contrary, similar STI across L1 and L2 in LP/Late bilingual group can be explained based on reduced organizational flexibility across languages which in 
turn were reflected as reduced possibility of achieving differential articulatory realizations in the two languages. The lack of organizational flexibility in speech motor control can partly explain why many late bilinguals have been reported to show reduced production proficiency and non native accent in L2 in many of the acoustic and perceptual studies (Flege \& Fletcher, 1992; Flege et al., 1999; Moyer, 1999; Munro, Flege \& Mackay, 1996; Oyama, 1973; Patkowski, 1990; Schimdt \& Flege, 1996; Yeni-Komshian, Flege \& Liu, 2000).

Although not within the scope of this study, it would be interesting to understand the influence of 'language use' on the articulatory motor routines. It seems like the higher usage of L1/L2 influences the articulatory variability of L2/L1. The more one uses 'L1/L2', more seems to be the influence on the internalization of articulatory motor routines specific to L1 or L2. Similar values of STI in LP/Late bilinguals probably suggests a possible association of reduced production proficiency of $L 2$ in the condition of continued usage of $L 1$, the notion proposed by Piske, Mackay \& Flege (2001). In the case of HP/Early group, both the languages were used to an equal extent but yet they maintained a differential articulatory variability patterns. As was evident, the mean STI in L1 was higher in HP/Early group compared to LP/Late group. This probably is supportive of the notion that there would be changes in the articulatory realization of L1 with the continued usage of $L 2$ too. This needs to be checked with the subjective ratings of production proficiency of bilinguals by competent judges, which were not carried out in this study.

The study design had few drawbacks such as limited sample size, and also the extrapolation of the results to non immigrant bilinguals is not possible due to the differences in the nature and distribution of bilingualism of this study compared to the reports of the western context. Although caution was exercised in minimizing the phonetic differences in the stimuli pairs, the individual variations in the prosodic aspect inherent in the production of each participant were not controlled and this could have influenced STI scores. The language switching paradigm used in this study needs to be replicated to understand its sensitivity to check language-motor interaction in bilinguals. The stimuli used in the study were limited to a single pair of bilabial phrase and therefore the performance of bilinguals across other classes of speech sounds needs further exploration. The constructed utterances were simple noun phrases and perhaps future studies could include other classes of stimuli pairs which are syntactically and semantically loaded (for e.g., verb phrases or clause structures) which could induce higher processing load on bilingual speech and hence could serve as an effective stimuli set to delineate the interaction between speech and language in bilinguals.

\section{Conclusion}

The study provided speech kinematic evidence for the differences in Kannada (L1) and English (L2) languages as well as the influence of L2 (English) language proficiency on L1 and L2 in typical Kannada English bilingual speakers. There were differences observed in the articulatory variability between L1 and L2 as reflected in the STI measures and this suggests the possibility of use of differential articulatory strategies at the higher order centers to differentiate the languages. The language proficiency in L2 seemed to be an important factor as seen from significant changes in mean STI scores of LL across L1 and L2. Furthermore, HP/Early bilinguals manifested higher mean STI variability of LL in L1 whereas similar STI was observed for L2 in LP/late bilinguals. The findings support the phenomenon of cross linguistic interference which seems to be dependent on the factor of language proficiency in L2. The study did not rule out the possible influence of biological/maturational and personal (motivation, language aptitude, higher cognitive abilities) factors and language use on the measured variability index, which could be addressed in future studies.

\section{Acknowledgements}

We thank the Director, All India Institute of Speech and Hearing, Manasagangothri, Mysore, India for allowing us to use the infrastructure of the institute and an opportunity to conduct this research.

We thank Dr. Rajapurohith (Retired Professor of Linguistics, CIIL, Mysuru, Karnataka, India) for his valuable suggestions and help in the preparation of stimuli for this study.

We express our sincere gratitude to Mr. Santhosh C.D for the valuable inputs provided during statistical analysis of this study and the participants who served as volunteers for the study.

We express our heartfelt thanks to Dr.H.S. Venkatagiri, Professor, lowa State University for his insightful thoughts on bilingualism and speech motor control and the discussions held were turned out to be highly fruitful in shaping this paper.

We express our sincere thanks to Richard Livings for putting his skillfull efforts in preparing MATLAB scripts to analyze the data.

We are humbled to express our sincere thanks to Dr. Anne Smith, Distinguished Professor, Purdue University, USA, for providing timely clarifications on Speech Motor Control and data analysis procedures of Speech Kinematics.

We appreciate and convey our sincere thanks to all the participants who gave their consent and participated in this study.

This was an independent study carried out by the authors and no government or non government funds were utilized for completing this study.

\section{REFERENCES}

1. Abrahamson, N., \& Hylstenstam, K. (2009). Age of onset and nativelikeness in a second language: Listener perception versus linguistic scrutiny. Language Learning, 59(2), 249-306. doi: 10.1111/j.1467-9922.2009.00507.x 
2. Ackermann, H., Hertrich, I., \& Scharf, G. (1995). Kinematic analysis of lower lip movements in ataxic dysarthria. Journal of speech and Hearing Research, 38, 1252-1259.

3. Birdsong, D. (1992). Ultimate attainment in second language acquisition. Language, 68, $706-755$. doi:10.2307/416851

4. Birdsong, D., \& Molis, M. (2001). On the evidence of maturational constraints in second language acquisition. Journal of Memory and Language, 44, 235-249. doi:10.1006/jmla.2000.2750

5. Boersma, P \& Weenink, D (2014). Praat: doing phonetics by computer (Version 5.3.72) [Computer software]. Retrieved 17 April 2014 from http://www.praat.org/

6. Bongaerts, T., Van Summeren, C., Planken, B., \& Schills, E. (1997). Age and ultimate attainment in the pronunciation of a foreign language. Studies in Second Language Acquisition, 19, 447-465.

7. Chakraborty, R. (2012). Invariant principles of speech motor control that are not language specific. International Journal of Speech-Language Pathology, 14, 520-528. doi: 10.3109/17549507.2012.686628

8. Chakraborty, R., \& Shanmugam, R. (2011). Influence of L2 proficiency on kinematic duration of single words: Real and novel word production by Bengali-English speakers. International Journal of Speech-Language Pathology, 13, 1-13. doi: 10.1080/17549507.2011.595824.

9. Chakraborthy, R., Goffman, L., \& Smith, A. (2008). Physiological indices of bilingualism: Oral motor coordination and speech rate in Bengali-English speakers. Journal of Speech, Language, and Hearing Research, 51, $321-332$. doi:10.1044/1092-4388(2008/024)

10. Chengappa, S., \& Devi, B. (2002) Developmental milestones of language acquisition in Indian languages: Kannada and Hindi (Unpublished ICSSR Research Project). All India Institute of Speech and Hearing, Mysore, India.

11. Costa, A., \& Santesteban, M. (2004). Lexical access in bilingual speech production: Evidence from language switching in highly-proficient bilinguals and L2 learners. Journal of Memory and Language, 50, $491-511$. doi:10.1016/j.jml.2004.02.002

12. Costa, A., Santesteban, M., \& Ivanova, I. (2006). How do highly proficient bilinguals control their lexicalization process? Inhibitory and Language-Specific Selection Mechanisms are both functional. Journal of Experimental Psychology: Learning, Memory and Cognition, 32, 1057-1074. doi:10.1037/0278-7393.32.5.1057

13. Flege, J. E. (1991). Age of learning affects the authenticity of voice-onset time (VOT) in stop consonants produced in a second language. Journal of the Acoustic Society of America, 89, 395-411. doi: 10.1121/1.400473

14. Flege, J. E. (1995). Second language speech learning: Findings and problems. In W. Strange (Ed.), Speech perception and linguistic experience: Theoretical and methodological issues (pp. 233-273). Timonium, MD: York Press

15. Flege, J. E., \& Fletcher, K. L. (1992). Talker and listener effects on degree of perceived foreign accent. Journal of Acoustical Society of America, 91, 370-389. doi:10.1121/1.402780

16. Flege, J. E., Frieda, E. M., \& Nozawa, T. (1997). Amount of native-language (L1) use affects the pronunciation of an L2. Journal of Phonetics, 25(2), 169-186.

17. Flege, J. E., Mackay, I. R. A. \& Meador, D. (1999). Native Italian subjects' production and perception of English vowels. Journal of Acoustical Society of America, 106, 2973-2987. doi: 10.1121/1.428116

18. Flege, J., Munro, M., \& MacKay, I. (1995). Factors affecting degree of perceived foreign accent in a second language. Journal of the Acoustical Society of America, 97, 3125-3134.

19. Flege, J. E., Schirru, C., \& Mackay, I. R. A. (2003). Interaction between the native and second language phonetic subsystems. Speech communication, 40, 467-491. doi: 10.1016/S0167-6393(02)00128-0

20. Flege, J. E., Yeni-Komshian, G. H., \& Liu, S. (1999). Age constraints on second-language acquisition. Journal of Memory and Language, 41, 78-104. doi:10.1006/jmla.1999.2638

21. Gick, B., Wilson, I., Koch, K., \& Cook, C. (2004). Language-specific articulatory settings: Evidence from interutterance rest position, Phonetica, 61, 220-233, doi: 10.1159/000084159

22. Goffman, L., \& Smith, A. (1999). Development and differentiation of speech movement patterns. Journal of Experimental Psychology: Human Perception and Performance, 25, 649-660. doi: 10.1037/0096-1523.25.3.649

23. Government of India, Ministry of Home Affairs, Office of the Registrar General and Census Commisioner, India (2011). Provisional population totals paper 1 of 2011 India series 1. Retrieved from censusindia.gov.in/2011-provresults/data_results_paper1_india.html.

24. Green, D. W. (1998). Mental control of the bilingual lexico-semantic system. Bilingualism: Language and cognition, 1(02), 67-81.

25. Grosjean (1982). Life with two languages. Cambridge, MA: Harvard University Press. 
26. Guion, S. G., Flege, J. E., Liu, S. H., \& Yeni-Komshian, G. H. (2000). Age of learning effects on the duration of sentences produced in a second language. Applied Psycholinguistics, 21(2), 205-228.

27. Ingram, D., \& Wylie, E. (1997). International second language proficiency ratings. Nathan, Queensland: Griffith University.

28. Jia, G., Aaronson, D., \& Wu, Y. (2002). Long-term language attainment of bilingual immigrants: Predictive variables and language group differences. Applied Psycholinguistics, 23(04), 599-621.

29. Lenneberg, E. H. (1976). Biological foundations of Language. New York: Wiley and Sons.

30. Mack, M. (1989). Consonant and vowel perception and production: Early English-French bilinguals and English monolinguals, Perception and Psychophysics, 46(2), 187-200.

31. MacKay, I., \& Flege, J. (2004). Effects of the age of second-language (L2) learning on the duration of L1 and L2 sentences: The role of suppression. Applied Psycholinguistics, 25, 373-396. doi:10.1017.S0142716404001171

32. Mackay, I., Flege, J. E., Piske, T., \& Schirru, C. (2001). Category restructuring during second language speech acquisition. Journal of Acoustical Society of America, 110, 516-528. doi: 10.1121/1.1377287

33. Magloire, G., Green, K. P. (1999). A cross-language comparison of speaking rate effects on the production of voice onset time in English and Spanish. Phonetica, 56, 158-185. doi: 10.1159/000028449

34. Maitreyee, R., \& Goswami, S. P. (2009). Language proficiency questionnaire: An adaptation of $L E A P-Q$ (Unpublished master's thesis). All India Institute of Speech and Hearing, Mysore, India.

35. Maner, K., Smith, A., \& Grayson, L. (2000). Influences of length and syntactic complexity on speech motor performance of children and adults. Journal of Speech Language and Hearing Research, 43, 560-573. doi:10.1044/jslhr.4302.560

36. Manjulakshi, L. (2003). A comparative phonology of Mysore district Kannada dialects, Languages in India, 3, Retrieved from http://www.languageinindia.com/oct2003/mysoredialect.html

37. MathWorks, Inc. (2012). MATLAB: The language of technical computing [Computer software]. Version 7.14, Release R2012a. Natick, MA.

38. Meuter, R. F. I., \& Allport, A. (1999). Bilingual language switching in Naming: Asymmetrical costs of language selection. Journal of Memory and Language, 40, 25-40. doi: http://dx.doi.org/10.1006/jmla.1998.2602

39. Moyer, A. (1999). Ultimate attainment in L2 phonology (The critical factors of age, motivation and instruction). Studies in Second Language Acquisition, 21, 81-108.

40. Moyer, A. (2004). Age, accent and experience in second language acquisition. Clevedon, UK: Multilingual Matters.

41. Munro, M. J., Flege, J. E., \& Mackay, I. (1996). The effects of age of second language learning on the production English vowels. Applied Psycholinguistics, 17, 313-334. doi: 10.1017/S0142716400007967

42. Nissen, S. L., Dromey, C., \& Wheeler, C. (2007). First and second language tongue movements in Spanish and Korean bilingual speakers. Phonetica, 64, 201-216. doi: 10.1159/000121373

43. Oyama, S. (1973). A sensitive period for the acquisition of a second language (Unpublished doctoral dissertation). Harvard University.

44. Patkowski, M. S. (1990). Age and accent in a second language: A reply to James Emil Flege. Applied Linguistics, 11, 73-89. doi:10.1093/applin/11.1.73

45. Perani, D., Paulesu, E., Galles-Sebastian, N., Dupoux, E., Dehaene, S., Bettinardi, V.,...Mehler, J. (1998). The bilingual brain: Proficiency and age of acquisition of the second language. Brain, 121, 1841-1852. doi:10.1093/brain/121.10.1841

46. Prema, K. S., \& Abhishek, B. P., \& Prarthana, S. (2009). Development of a test for language proficiency in bilinguals (Unpublished AIISH Research Fund Project). All India Institute of Speech and Hearing, Mysore, India.

47. Sasisekaran, J., \& Weisberg, S. (2013). The effects of cognitive-linguistic variables and language experience on behavioural and kinematic performances in nonword learning, Journal of Psycholinguistic Research, 42, 175-190. doi: 10.1007/s10936-012-9218-2.

48. Sadagopan, N., and Smith, A. (2008). Developmental changes in the effects of utterance length and complexity on speech movement variability. Journal of Speech, Language, and Hearing Research, 51, 1138-1151. doi: $10.1044 / 1092-4388(2008 / 06-0222)$

49. Schmidt, A. M., \& Flege, J. E. (1996). Speaking rate effects on stops produced by Spanish and English monolinguals and Spanish/English bilinguals. Phonetica, 53, 162-179. doi:10.1159/000262196 
50. Sharkey, S. G. \& Folkins, J. W. (1985). Variability of Lip and Jaw Movements in Children and Adults: Implications for the Development of Speech Motor Control. Journal of Speech Language and Hearing Research, 28, 8-15. doi:10.1044/jshr.2801.08

51. Smith, A., \& Goffman, L. (1998). Stability and patterning of speech movement sequences in children and adults. Journal of Speech, Language, and Hearing Research, 41, 18-30. doi:10.1044/jslhr.4101.18

52. Smith, A., Johnson, M., McGillem, C., \& Goffman, L. (2000). On the assessment of stability and patterning of speech movements. Journal of Speech, Language, and Hearing Research, 43(1), 277-286

53. Smith, A., \& Zelaznik, H. N. (2004). Development of functional synergies for speech motor coordination in childhood and adolescence. Developmental Psychobiology, 45, 22-33. doi:10.1002/dev.20009

54. Smith, A., Goffman, L., Zelaznik, H. N., Ying, G., \& McGillem, C. (1995). Spatiotemporal stability and patterning of speech movement sequences. Experimental Brain Research, 104, 493-501. doi:10.1007/BF00231983

55. Stathopoulos, E. (1995). Variability revisited: An acoustic, respiratory, and aerodynamic comparison of children and adults during speech. Journal of Phonetics, 23, 67-80. doi: 10.1016/S0095-4470(95)80033-6

56. Walsh, B., \& Smith, A. (2002). Articulatory movements in adolescents: Evidence for protracted development of speech motor control processes. Journal of Speech, Language, and Hearing Research, 45, 1119-1133. doi:10.1044/1092-4388(2002/090)

57. Wartenburger, I., Heekeren, H. R., Abutalebi, J., Cappa, S. F., Villringer, A., Perani, D. (2003). Early setting of grammatical processing in the bilingual brain. Neuron, 37, 159-170. doi:10.1016/S0896-6273(02)01150-9

58. Wilson, I., \& Gick, B. (2014). Bilinguals use language specific articulatory settings. Journal of Speech, Language, and Hearing Research, 57, 361-373. doi:10.1044/2013_JSLHR-S-12-0345

59. Yeni-Komshian, G. H., Flege, J. E., \& Liu, S. (2000). Pronunciation proficiency in first and second languages of Korean-English Bilinguals. Bilingualism: Language and Cognition, 3 (2), 2000, 131-49.

60. Zimmermann, G. N. (1980). Articulatory dynamics of fluent utterances of stutterers and nonstutterers. Journal of Speech and Hearing Research, 23, 95-107. 